\title{
Personal values about change and status quo influence outsiders' appraisals of intergroup conflict
}

\author{
Alexander K Saeri, Aarti Iyer, \& Winnifred Louis \\ The University of Queensland \\ The University of Sheffield
}

This document is an author pre-print originally uploaded to PsyArXiv

10 December 2016

\section{Author Note}

Alexander K. Saeri and Winnifred R. Louis, School of Psychology, The University of Queensland, Australia. Aarti Iyer, Department of Psychology, The University of Sheffield, United Kingdom.

Correspondence concerning this article should be addressed to Alexander K. Saeri, School of Psychology, The University of Queensland QLD 4072, Australia. E-mail: alexander@aksaeri.com. 


\begin{abstract}
In three studies, we build on Schwartz's $(1992,1994)$ work on universal values to explore the content and structure of individuals' change and status quo values, to distinguish these values from other political ideologies and orientations, and to investigate the role of these values in shaping appraisals of intergroup conflict and collective action. In Study 1, we investigated the themes that underpin beliefs about change and the status quo. In Study 2, we created and validated separate measures to assess endorsement of change and status quo values, and show that they are distinct from related ideologies such as Social Dominance Orientation and Right-Wing Authoritarianism. Study 3 demonstrated that change values - but not status quo values - influence the contextual appraisals that outsiders make when they encounter a hypothetical group conflict for the first time. Endorsing change leads to appraisals of the conflict that are supportive of a low-status citizen protestor group, and increases collective action intentions on behalf of this group. In addition, endorsing change leads to appraisals that are not supportive of a high-status government group in conflict, and decreases collective action intentions on behalf of this group.
\end{abstract}

Keywords: values, group conflict, collective action 


\section{Personal values about change and status quo influence outsiders' appraisals of intergroup conflict}

Each of us holds values that are central to our self-concept. These values are expressed in our attitudes and behaviours, and help to shape our responses to new situations. In a psychological sense, values are goals that transcend any single situation and help form the personal lens through which we see and react to the world, thus serving as "guiding principles in the life of a person" (Schwartz, 1994, p. 21). A person who values power, for example, believes that power is a goal in and of itself, and desires to gain power. Endorsing power as a personal value can thus shape that person's beliefs and actions across a range of situations and contexts: they will act upon their world so as to achieve power, while simultaneously constructing a worldview that justifies those actions (Schwartz, 1994). Values can also serve as standards against which situations and behaviours are judged. If a person perceives that their values have been violated or betrayed, they will be motivated to take action to defend their worldview and restore the world to rights.

Collective action, where an individual takes action in support of a group's goals and interests, seems an obvious situation in which values would be both salient and powerful. A person may be motivated to take collective action if the goals of their group were aligned with a personal value (e.g., the desire for security), or when their group was suffering as a result of some transgression against a personal value (e.g., where a terrorist act had been committed against the group, violating that group's security). Altruistic values have been demonstrated to motivate proenvironmental action, and international harmony and equality values can motivate political protest (e.g., Stern et al., 1999; Braithwaite, 1994). But social psychological investigations of collective action have largely ignored personal values and other stable individual differences to instead focus on how appraisals of the specific social context — especially, the strength of one's connection with the acting or transgressed-upon group — can influence one's likelihood to take action (Wright, 2010; van Zomeren, 2013). Instead, individuals are motivated to act by their social identification with the relevant group, felt anger or perceived injustice at the actions of an opposing group, and perceived 
efficacy of the relevant group (van Wright, 2010; van Zomeren, 2013). The focus on contextuallybound appraisals is appropriate when investigating collective action in response to a specific instance of intergroup conflict. Most collective action work aligns with this paradigm, and tends to study antecedents of collective action for members of disadvantaged groups that challenge more advantaged groups on the basis of their unjust disadvantage (for a meta-analysis, see van Zomeren, Postmes, \& Spears, 2008).

In this paper, we expand the view of collective action research to consider actors beyond members of the belligerent groups. Theories of collective action argue that third parties within the conflict context and outsiders beyond the conflict context may intervene through collective action (Simon \& Klandermans, 2001; Subašić, Reynolds, \& Turner, 2008, Thomas, McGarty, \& Mavor, 2009), though there is much less empirical work for this position (for exceptions, see Saeri, Iyer, \& Louis, 2015; Subašić, Schmitt, \& Reynolds, 2011). The psychological pathway by which third parties and outsiders come to appraise a conflict and take collective action is also relatively unexplored (but see Saeri et al., 2015). New research suggest that stable, personal beliefs including moral convictions, Social Dominance Orientation, and Right-wing Authoritarianism can shape appraisals of intergroup conflict and subsequent collective action (Saeri et al., 2015; van Zomeren, Postmes, \& Spears, 2012; van Zomeren, Postmes, Spears, \& Bettache, 2011). In this work, we investigate how personal values might shape an outsider's appraisals of an external group conflict and lead to collective action.

\section{Personal values and collective action}

The diverse investigations of the relationship between values and political behaviour have conceptualised and operationalised personal values in many different ways. Schwartz (1994) defined ten values that he described as universal across humanity: power, achievement, hedonism, stimulation, self-direction, universalism, benevolence, conformity, tradition, and security. Although different cultures and individuals might espouse different specific values within this set, all cultures recognise and engage with the ten values. The values can be organised into a theoretical structure, 
in which some values are similar in their goals (e.g., power, achievement), and some values are in opposition (e.g., conformity, self-direction; Schwartz, 1992; 1994; Schwartz, Caprara, \& Cecchione, 2010). Schwartz describes two key dimensions of opposition that form "second-order values": Openness to Change (stimulation, self-direction) vs. Stability (conformity, tradition, security) and Self-enhancement (power, achievement, hedonism) vs. Self-transcendence (universalism, benevolence).

Research that has examined how values may motivate political action typically investigates a single dimension, or proposes novel dimensions that fit conceptually with the existing theoretical structure. Braithwaite (1994) argued that Schwartz's value structure could be reframed as a twodimensional model of political values, and found that people who endorsed the value of selftranscendence (relabelled as equity) more strongly supported left-wing policies and were likely to take political action to support such policies compared with whose people who endorsed the value of stability (relabelled as law and order). Stern and colleagues adapted the self-transcendence dimension as environmental altruism to investigate what led individuals to engage in proenvironmental behaviour. In this work, values form the first of three steps for action, via beliefs and personal norms (Stern \& Dietz, 1994; Stern, Dietz, Abel, Guagnano, \& Kalof, 1999). Endorsing a personal value leads to the belief that one has a personal responsibility to uphold those values. That belief then prescribes a personal norm of action (Stern, Dietz, \& Kalof, 1993). Schwartz and colleagues (2010) have used universal personal values—relabelled as "basic" values, and with the Stability cluster relabelled as "Conservatism"- - to organize explicitly political values (e.g., law and order, equality).

It is clear that personal values influence political thinking and action. In this paper we directly examine the content and structure of Schwarz' primary second-order value dimension: Openness to Change, and Status Quo (which Schwartz labels "conservation") in the interests of establishing a "ground truth" from which to investigate this question. We choose to relabel the 
Conservation value as Status Quo, in order to avoid confusion with the political ideology of conservatism and the environmental ideology of conservationism.

We chose to focus on change and status quo orientations in this paper for two reasons. Schwartz (1992; 1994) proposed that change and conservation (status quo) formed the first dimension of differentiation among all ten universal human values. This dimension is a logical place to start in any investigation of the role played by values in shaping responses to a new context. Understanding how change and status quo influence appraisals of group conflict and shape collective action is a first step in integrating the rich theoretical and empirical work on values with the well-established collective action literature. Second, both change and status quo values align with the goals expressed by social movements and political actions today. For instance, Hong Kong citizens engaged in collective action in 2014 to retain the status quo, preserving autonomy over the upcoming 2017 elections (Kaiman, 2014). In contrast, Canadians protested for a change in Canada's drug laws, with the goal of legalising marijuana (The Canadian Press, 2014). To the extent that change and status quo are emphasised in social movements' slogans and speeches, movement organizers must expect that such values can mobilize action. We investigate this expectation in the current work.

\section{Developments in collective action research}

The social context within which group conflict takes place influences when and how individuals will be mobilized to act. Embedded in the context are the content and meaning of group membership, status and power differences between groups, and the history of their interaction and conflict. Typically, collective action research focuses on antecedents of collective action that are bound to the context. For example, it is social identification with a disadvantaged group that forms the core motive to act. When individuals experience anger as in response to a collective injustice, or perceive that their group has the power (efficacy) to achieve its goals, they are also more willing to act (van Zomeren et al., 2008; Thomas et al., 2009). These context-centred appraisals are the focus of most current models of collective action (e.g., Thomas et al., 2009; van Zomeren et al., 2008). 
However, not all potential collective actors are embedded within the conflict context, where context-specific appraisals are most relevant. Individuals who are psychologically (and geographically) external to group conflict may appraise the conflict quite differently from members of the belligerent groups. Work investigating these "outsiders" to conflict has typically conceptualised them as members of majority audiences who can influence the conflict by endorsing one of the two conflicting groups through a process of self-categorization, identification, and action on one group's behalf (Simon \& Klandermans, 2001; Subašić et al., 2008). However, such an audience is already part of the intergroup context and thus has at least a minimal connection to, and understanding of, the groups involved in the conflict. Their psychological experiences of, and responses to, the conflict may be quite different from those outsiders who in our model are truly external to the conflict-not part of the nation, political entity or society in which the conflict is occurring. We believe that personal values can help explain why outsiders would come to support one group or another in conflict, as they may form the basis for an opinion-based group.

Opinion-based groups are those where individuals feel psychologically connected by a shared belief, rather than a demographic or social characteristic, and may engage in collective action to support or defend that belief (Bliuc, McGarty, Reynolds, \& Muntele, 2007). Values are universal (i.e., every human endorses each value to varying degrees; Schwartz, 1994), values specify goals that transcend a specific situation, and values compel individuals to act in pursuit of that goal. Thus universal personal values regarding change or the status quo may provide the shared psychological basis for a value-based group that, as a fact of its creation, is mobilized to take collective action in order to realise that shared value. In this paper, we argue that personal values can shape appraisals of novel external conflicts much like they shape appraisals of other new situations. Indeed, outsiders are an ideal population in which to investigate the potential role of values in collective action. A lack of information about the conflict context would lead outsiders to use their pre-existing personal values as an interpretive lens when encountering a novel group conflict for the first time. 


\section{Extending the pathways to action}

Core to most models of collective action are context-specific appraisals (e.g., identification, injustice, and efficacy) that directly predict collective action intentions and behaviour. However, recent work has begun to investigate how more stable, personal beliefs may shape these more proximal appraisals. Van Zomeren and colleagues (van Zomeren, Postmes, \& Spears, 2012; van Zomeren, Postmes, Spears, \& Bettache, 2011) have shown that personal moral convictions about group conflict (e.g., believing that mainland Chinese deserve greater political freedom) can indirectly predict collective action intentions by fostering identification with the affected group. Saeri et al. (2015) have shown that personal political ideologies of Social Dominance Orientation (Pratto, Sidanius, Stallworth, \& Malle, 1994) and Right-wing Authoritarianism (Altemeyer, 1981) can shape proximal appraisals both sympathetic to a disadvantaged group (e.g., Russian protestors against government corruption) and sympathetic to an advantaged group (e.g., the Russian government with a goal of quelling protests). In each of these cases, appraisals about the social context that predict collective action — generally considered as independent variables in collective action models and research - are considered as outcome variables, influenced by stable personal beliefs. We argue that personal values of change and status quo may play a similar but unique role in explaining the appraisals that individuals make about a context of conflict. The more proximal context-specific variables may then be conceptualised as mediators of the belief-collective action relationship, as described in van Zomeren (2013).

Conceptualising these stable, personal beliefs as predictors thus helps to explain why an individual may identify strongly or weakly with a group engaged in conflict, or why an individual feels that a group's (dis)advantage is just or unjust. This is especially important among individuals not directly involved in the conflict or who have no pre-existing group membership (Saeri et al., 2015). In this paper we seek to contribute to the literature on more stable, distal predictors of appraisals and subsequent collective action by investigating the role of personal values of change and status quo. Values mobilize individuals to act in order to achieve the goal that forms the core of 
the value: an individual who values change should not merely prefer change, but take action in order to realise that change. They would view intergroup conflicts through a lens that is sensitive to promotion or prevention of change. As the opposite on the value dimension, we would expect that an individual would prefer the status quo, and act in order to reinforce or restore a status quo under threat. In this way, personal values can have collective consequences. Because Schwartz' basic values have been shown to be associated with political values (Schwartz et al., 2010), demonstrating the utility of social change and status quo values in research must distinguish between the values and political ideologies such as right-wing authoritarianism and social dominance.

\section{Overview of present research}

In this paper we investigate the extent to which endorsing change the status quo as values can shape appraisals of group conflict and subsequent collective action to support the parties involved in the conflict. To advance this aim, we consider three questions. First, what is the content of people's change and status quo values? Second, how are change and status quo values different from each other and from established political ideologies and orientations? Finally, can change and status quo values uniquely and significantly predict outsiders' appraisals of a novel group conflict? Study 1 explores the first question with a mixed-method investigation of what change and status quo values mean to individuals, in the absence of a political or conflict context. Study 2 examines the second question with a cross-sectional survey in which we validate new measures of change and status quo values derived from key themes identified in Study 1. Specifically, we use Exploratory Factor Analysis to differentiate the values of status quo and change from related political ideologies such as Social Dominance Orientation (Pratto et al., 1994), Right-Wing Authoritarianism (Altemeyer, 1996), System Justification (Kay \& Jost, 2003), and political conservatism. Study 3 investigates the final question with a two-stage study. Change and status quo values are measured at Time 1; at Time 2, participants encounter a novel group conflict and make context-specific appraisals (e.g., group identification, felt anger, perceived group efficacy) in support of both the 
high-status (relatively advantaged) and low-status (relatively disadvantaged) groups in that conflict, including their willingness to take collective action in support of each group.

\section{Study 1}

We first sought to investigate the content and structure of individuals' change and status quo values. The Schwartz Value Survey (SVS; Schwartz, 1992) or the Portrait Values Questionnaire (PVQ; Schwartz et al., 2001) ask participants to endorse specific items that are designed to reflect each of the universal values. However, our aim in this study was for a comprehensive illustration of how people think about values, rather than responses to pre-specified items. We conducted a mixedmethod study in which participants reflected upon what change and status quo as values meant to them personally, and rated their endorsement and importance of each value. Thematic analysis was used to discover the content of each value. Participants' endorsement and importance ratings were used to investigate whether the two values were associated, and in what direction.

\section{Method}

Participants and Procedure. Fifty-four US residents were recruited using Amazon Mechanical Turk. Participants were paid $\$ 0.50$ to participate in the online study. Participants ranged in age from 19 to $64(\mathrm{M}=33.64, \mathrm{SD}=11.81)$ years. Twenty-two $(41 \%)$ were female; four did not disclose their sex. Most participants $(n=39,72 \%)$ reported their race as White / European American, three were African American (6\%), three were Asian American (6\%), two were Hispanic / Latino, one was Native American / American Indian. Six did not disclose their race. The data for this study were collected in 2013.

Measures. Participants were asked to indicate whether they thought that "change" and, separately, "the status quo" were important in their lives. Participants who responded "yes" were asked "What does valuing [change/status quo] mean to you? Think as broadly as possible about [change/status quo] as an ideal in as many aspects of your life as you can." Participants who responded "no" were also asked to elaborate on this position, e.g., "What does not valuing 
[change/status quo] mean to you?" Participants then rated the importance of change and status quo in their lives (1: not at all; 9: a great deal).

\section{Results}

Association between change and status quo values. In total, 38 (70\%) participants indicated that they valued change. In contrast, 19 (35\%) participants indicated that they valued the status quo. Most $(n=41)$ participants believed that valuing change and valuing the status quo were mutually exclusive. Further, participants who rated change as more important tended to rate status quo as less important, and vice versa, $r(51)=-.58, p<.001$. Together, these results indicate that change and status quo are distinct and opposing values, broadly supporting Schwartz' (1994) theoretical structure, which places change and status quo in opposition.

Thematic analyses. We conducted thematic qualitative analyses of the open-ended responses to the questions "what does change [status quo] mean to you?", guided by the process described in Braun and Clarke (2006). There were two coders: the first author, and a graduate student who was naïve to the values literature and the premises of the study. The coders worked independently to read through all responses and identify underlying themes. Each participant's response was then coded as reflecting one or more themes. When the themes identified in each response differed between coders, the discrepancy was discussed. We distinguished between frequently recurring themes and less frequent themes. Below we present the key themes identified by the coders for each value.

Themes identified in responses to valuing the status quo question. Predictability and security were identified as recurrent themes in participants' responses to the question, "what does the status quo mean to you?". Two less frequent themes also emerged: fear of disruption caused by change, and the importance of respecting tradition.

Predictability. Some participants stated that their desire for a predictable life was one of the reasons they valued the status quo. Knowing what to expect next, and feeling comforted by routine were often referenced. For example: 
"Status quo to me means sticking to the way things are. Sticking to a sort of routine and not straying too far from the norm. I prefer to keep things close to routine."

Security. Participants noted that the status quo was safer than the alternative. Embracing the status quo meant that people could be certain that they would not lose what they had worked for. For example:

"I think in life I strive to maintain the status quo. I like the security that it brings, and it makes me feel better."

"I have worked for decades to gather what little I have, and I am satisfied with it. I maintain a small business, and a lovely family home. Holding what I have is dear to me."

Fear of change. A number of participants explicitly described changes to their current life as disruptive and unwanted, and made reference of how change would threaten their predictability and security. For example:

"I value the status quo because I spent my early years very disorganized and my life was very fluid. I had a lot of problems succeeding in things I tried, and it was hard to gain a foothold of success. Since I've gotten a routine I like to stick to, I've been able to advance in life in my career, family, etc."

"I don't like change very much at all. I really like things to stay how they are. I realize it's not possible, but in my ideal world, I'd like things not to change."

Respect for tradition. A few participants described valuing the status quo as a way of respecting the existing order of the world and the work of those who came before them. For example:

"I value the status quo because it represents the past and what has work [sic] in the past." "I do think that some things are better left they [sic] way they are. For example, the US has a rich and admirable history of great heroes who have made this country great. We have holidays to honor great events like the Fourth of July. These traditions of celebrating 
holidays, respecting our military for defending our country serve as a respect for the privileges we are given by being US citizens."

Themes identified in responses to valuing change question. Growth, novelty, and avoidance of stagnation were each identified as major, recurring themes in participants' responses to the change value open-ended question. The need to adapt to the inevitability of change was identified as a less frequent theme.

Growth. Participants frequently described change as important for improvement in themselves and in the world around them. Embracing change was seen as necessary to progress as a person. For example:

"Change reflects that I am growing and learning from experiences, but more importantly, that I am applying what I have learned and experienced to improve the quality of my life and my decisions."

"I think we should always be striving to grow and evolve as people. We should also work to change our surroundings to make them better whenever possible."

"I think change is important in life because it the only way you can progress as a person." Novelty. Distinct from self-improvement, the theme of novelty focused on change being valued simply because it heralded the arrival of new experiences or situations. For example:

"Change can bring on new ideas, new places to be, new ways of looking at things."

Avoidance of stagnation. Contrasting directly with the status quo theme of fear of change, this theme explicitly described how adhering to the status quo would lead to a failure to flourish. Participants referred to life as too safe and easy in the absence of change. For example:

"Change is important to me because without change life would be extremely static and boring... If we didn't have change then I would get extremely bored of doing the same things for 70 years, so change is very important to me." 
Adapting to inevitability. A few participants described change as inescapable, and said that change would happen whether they wanted it or not, thus it was better to embrace change rather than reject it. For example:

"Change is a constant in the universe. I would rather value it than fight against it."

"Being able to change and adapt is essential for various things in life. It is being able to recognize your own flaws and alter your behavior to accomodate. Being able to recognize and adapt to change is important."

\section{Discussion}

In this first study we sought to uncover the content and structure of change and status quo values in individuals. Our results align with elements of existing work on universal values, including the general oppositional structure of change "versus" status quo, conceptualised by Schwartz (1994) as second-order values. When we asked participants to describe what valuing change and the status quo meant to them, their responses included themes that were broadly similar to the first-order values described by Schwartz (1994; 2010).

In Schwartz' work, change is described as a second-order value that encapsulates the firstorder values of self-determination and stimulation. In this study, participants described the following themes underlying their valuing of change: growth, novelty, avoidance of stagnation, and adapting to inevitability. We see the closest alignment between our results and Schwartz' values as follows: novelty and avoidance of stagnation themes are analogous to stimulation as a value, and growth and adapting to inevitability are analogous to self-determination as a value. In Schwartz' work, the second-order stability (or conservation) value encapsulates tradition, conformity, and security. In the present study, valuing the status quo was underpinned by beliefs about predictability, security, fear of change, and respect for tradition. The theme that we labelled as predictability aligns with Schwartz' basic value of conformity in that both endorse the following of existing social expectations and/or norms (Schwartz, 1994). The themes we labelled with security and fear of change align with the basic value of security in that both endorse safety and stability of 
relationships and the social order; and the respect for tradition theme aligns with the basic value of tradition in that both endorse respect and commitment to established or historical tradition (Schwartz, 1994). Participants' unprompted responses to our questions about the content of change and status quo values were thus consistent with established findings for the full suite of ten universal human values (e.g., the Schwartz Value Survey; Schwartz, 1992). Since the aim of the current research is to investigate the distinct roles of change and status quo values in shaping appraisals of group conflict, and not assess all ten lower-order universal values, we chose to build from the results of Study 1 in creating quantitative measures of how strongly outsiders endorse change and status quo as values. These measures are investigated in more detail in Studies 2 and 3.

The change and status quo values are often described in previous work as the opposite anchors of a dimension (Schwartz, 1992; Schwartz et al., 2010). This implies that those who endorse the value of change are likely to reject the value of the status quo, and vice versa. Strong evidence to support this argument would thus be a perception that these values were exclusive, and a negative correlation between endorsing change and endorsing status quo values. The majority of people described these values as exclusive, and we did see a strong negative correlation between the two values.

In this study we have identified key themes that describe the content of change and status quo values. We also found some preliminary evidence that suggests these two values are independent, rather than opposite anchors of a single value dimension. In Study 2, we seek to confirm that these values are conceptually distinct from each other, as well as from established political attitudes that may be salient in the context of intergroup conflict.

\section{Study 2}

In this study we aimed to construct a quantitative measure of the degree to which a person values change and values the status quo. This is a necessary intermediate step in being able to test our general claim that personal values can shape context-bound appraisals of group conflict and inequality. Recent work in collective action has found that personal ideological orientations such as 
Social Dominance Orientation (SDO; Pratto et al., 1994) and Right-Wing Authoritarianism (RWA; Altemeyer, 1996) are associated with context-bound antecedents of collective action, such as anger towards disadvantaged groups and identification with advantaged groups (Saeri et al., 2015). It is possible that there is conceptual overlap between these ideologies and personal values of change and/or status quo. This is especially so for RWA, which is theorised to include as an element the desire for security and stability, which is also reflected in the themes identified for valuing the status quo in Study 1 (Duckitt \& Sibley, 2009). SDO and RWA are related to the general ideological orientation of political conservatism (Feldman, 2013) and system justification (Kay \& Jost, 2003), and recent values work have explicitly linked Schwartz' (1994) values with political beliefs and ideologies (Schwartz et al., 2010). Therefore it is important in Study 2 to determine whether change and status quo values are distinct from endorsing particular political ideologies and attitudes, including SDO, RWA, and system justification.

\section{Method}

Participants. We recruited 100 U.S. residents from Amazon Mechanical Turk as participants in this study, with a payment of $\$ 0.50$ for their time. Participants were aged 18 to 69 years $(\mathrm{M}=34.26, \mathrm{SD}=11.91)$ and $58 \%$ were male. The majority $(73 \%)$ were White or European American; 15\% were Asian American, 7\% were Hispanic or Latino, and 4\% were African American. All participants had completed their high school diploma; 45\% had attained a Bachelor's degree. The data for this study were collected in 2013.

Measures. Except where specified, all responses were provided on a 1-7 response scale ranging from "strongly disagree" to "strongly agree."

Endorsement of the Status Quo as a value. We developed self-report items that drew on the four status quo themes identified in Study 1 (predictability, security, avoiding change, and respecting tradition). The content of each item was adapted from prototypical participant responses

to a theme in Study 1. For example, the full response of a Study 1 participant, "I think in life I strive to maintain the status quo. I like the security that it brings, and it makes me feel better," was 
adapted as the item "I like the security that comes with things staying the same". This item reflected the security theme. In total, 11 items were developed in order to represent the themes identified in Study 1 (see Table 1).

Endorsement of Change as a value. We developed items based on each of the themes identified in Study 1 (growth, novelty, avoidance of stagnation, and adaptation to inevitability). We adapted responses from Study 1 to reflect each theme. Example items include, "I value change because it leads to progress" (growth theme), "Change is a constant in the universe, so it's best to embrace it" (inevitability theme), "Without change, society would fall into an entirely predictable routine" (avoidance of stagnation theme). A total of 9 items were developed to assess participants' change values (see Table 1).

Social Dominance Orientation. We adapted a recent revision of the Social Dominance Orientation (SDO) measure to assess participants' preference for social dominance (Ho et al., 2012). This 16-item measure includes both positively- and negatively-worded items. An example of a positively worded item is: "Some groups of people are simply inferior to other groups". An example of a negatively worded item is "We should work to give all groups an equal chance to succeed". After recoding, the items were averaged to create a single measure of SDO.

Right-wing Authoritarianism. We selected nine items from the original 30 item Right-Wing Authoritarianism (RWA; Altemeyer, 1996) measure for brevity. The nine items included have been used in previous work (e.g., Saeri et al., 2015) and are the three highest-loading items for each subscale of submission, aggression, and conventionalism (Mavor, Louis, \& Sibley, 2010). One example item is: "The real keys to the 'good life' are obedience, discipline, and sticking to the straight and narrow". All nine items were averaged to create a single measure of RWA.

System justification. We adapted five items from a published measure of System Justification (Kay \& Jost, 2003) to measure beliefs that the world as a whole was just and fair, rather than just the society that a person lives in. An example item was "In general, you find 
societies in the world to be fair". The five items were averaged to create a single measure of System Justification.

Political conservatism. We used two items to measure political conservatism on social and economic issues. Participants indicated the degree to which they thought of themselves as "very conservative" (1) to "very liberal" (7) on each set of issues.

\section{Results}

Exploratory Factor Analysis. In this study, we sought to demonstrate that personal values of change and status quo are statistically distinct from each other, and also distinct from other established, politically-focused ideological orientations. To do so, we conducted an exploratory factor analysis. We included the 51 items that make up the following measures: endorsement of change as a value, endorsement of status quo as a value, SDO, RWA, System Justification, and political conservatism. We used maximum likelihood extraction with oblimin rotation, and retained all factors with Eigenvalues above 1. In total, 11 factors were retained, explaining $77 \%$ of the variance. Inspection of the scree plot revealed a discontinuity at the sixth factor, which indicates that after the sixth extracted factor, additional factors each accounted for a less meaningful proportion of the variance among items. A comprehensive list of factor loadings is presented in Table 1. 


\section{Table 1}

\section{Exploratory Factor Analysis for all measured items in Study 2.}

\begin{tabular}{llllllllllllll}
\hline & \multicolumn{1}{c}{ Component } \\
\cline { 2 - 10 } Item & 1 & 2 & 3 & 4 & 5 & 6 & 7 & 8 & 9 & 10 & 11 \\
\hline
\end{tabular}

Social Dominance Orientation

Having some groups on top really benefits everybody

It's probably a good thing that certain groups are at the top and other groups are at the bottom

An ideal society requires some groups to be on top and others to be on the bottom

Some groups of people are simply inferior to other groups

Groups at the bottom are just as deserving as groups at the top

No one group should dominate in society

Groups at the bottom should not have to stay in their place

Group dominance is a poor principle

We should not push for group equality

We shouldn't try to guarantee that every group has the same quality of life

It is unjust to try to make groups equal

Group equality should not be our primary goal

We should work to give all groups an equal chance to succeed

We should do what we can to equalize conditions for different groups

No matter how much effort it takes, we ought to strive to ensure that all groups have the same chance in life

Group equality should be our ideal

Right-Wing Authoritarianism

What our country really needs is a strong, determined leader who will crush evil, and take us back to our true path

Once our government leaders give us the "go ahead," it will be the duty of every patriotic citizen to help stomp out the rot that is poisoning our country from within

The situation in our country is getting so serious, the strongest methods would be justified if they eliminated the troublemakers and got us back to our true path

There is nothing wrong with premarital sexual intercourse

Everyone should have their own lifestyle, religious beliefs, and sexual preferences, even if it makes them different from everyone else

There is no "ONE right way" to live life; everybody has to create their own way

Obedience and respect for authority are the most important virtues children should learn

The real keys to the "good life" are obedience, discipline, and sticking to the straight and narrow

It may be considered old fashioned by some, but having a normal, proper appearance is still the marker of a gentleman and, especially, a lady

Status Quo values (themes)

I prefer to stay with what is familiar (Security)

It feels safer to stay with what is familiar (Security)

I like the security that comes with maintaining the status quo (Security)

I like the security that comes with things staying the same (Security) 
In my ideal world, I'd like things not to change (Avoid Change) $\quad .74$

I feel more comfortable to have things the same than things constantly changing (Routine)

I like routine in the world (Routine)

Maintaining the status quo can preserve important positive qualities and traditions (Respect for tradition)

It is important to respect the status quo (Respect for tradition)

Change values (themes)

Being open to change can bring new and better opportunities in life (Novelty)

Change opens the door to new possibilities (Novelty)

I value change because it leads to progress (Growth)

People and societies must embrace change in order to grow and become better (Growth)

Society's potential for growth and positive change is limited when we maintain the status quo (Growth)

Change is a constant in the universe, so it's best to embrace it (Adapting to inevitability)

Change is inevitable, and thus we should try and make the most of the opportunities that it presents (Adapting to inevitability)

If everything remained the same all the time, life would become stagnant and stale (Avoiding stagnation)

Without change, society would fall into an entirely predictable routine

(Avoiding stagnation)

System justification

In general, you find societies in the world to be fair

In general, the political systems of societies in the world operate as they should

For societies in the world, most policies serve the greater good

Political conservatism

Economic conservatism

Note. Factor loadings <.30 are not displayed. Bolded items were retained in Study 3 measures of change and status quo values. 
The majority of the status quo values items (9 of 11) loaded highly (>.72) onto a single factor. The majority of the change items (6 of 9) also loaded highly (>.69) onto a different single factor. The highly-loading items can thus be used as a reliable measure of change values and, separately, status quo values. The remaining items either displayed cross-factor loadings, loaded onto another factor, or did not load highly onto any factor. As a whole, these results indicate discriminant validity, in that the items measuring change and status quo values represent distinct constructs, consistent with the findings from Study 1. In addition, the two factors identified for change and status quo values were also distinct from the factors that captured items from the other political ideology and attitude measures.

Inspection of the factor loadings for the other items revealed that many loaded across multiple factors, including half (8) of the SDO items and a third (3) of the RWA items. Although a clear factor structure did not emerge for measures of SDO and RWA, the internal structure of these constructs has been explored at length elsewhere, with SDO comprising two components (Ho et al., 2012), and RWA comprising three components (Mavor, Louis, \& Sibley, 2010). In summary, endorsing change status quo as values were found to be statistically distinct from political ideologies and attitudes. The results of the factor analysis suggest that the items we created could be used to form a reliable and valid measure of change and status quo values.

Change and Status Quo measure validity. We created composite measures for each construct, including change and status quo values. Measures for change and status quo were created from their highly- and singly-loading items (see bolded items in Table 1). Measures for SDO and RWA were created by averaging all their items, as in previous work investigating ideological orientations (e.g., Sibley \& Duckitt, 2010b). Means, standard deviations, measure reliability, and bivariate correlations are presented in Table 2. The reliability of the newly-constructed measures of Change and Status Quo in Study 2 was high for each measure $(\alpha>.90)$. SDO and RWA were significantly and positively associated with status quo values. The more a participant endorsed social dominance and right-wing authoritarianism as ideologies, the more they valued the status 
quo. In contrast, SDO was significantly negatively associated with endorsement of change as a value. The more a participant endorsed social dominance, the less they valued change. Status quo values, but not change values, were significantly and positively associated with political conservatism. 
Table 2

Descriptive statistics and bivariate correlations for Study 2 variables.

\begin{tabular}{|c|c|c|c|c|c|c|c|c|c|}
\hline & \multirow[b]{2}{*}{ Variable } & \multirow[b]{2}{*}{ Mean } & \multirow[b]{2}{*}{$\mathrm{SD}$} & \multirow[b]{2}{*}{ Reliability $^{\mathrm{a}}$} & \multicolumn{5}{|c|}{ Correlations } \\
\hline & & & & & 1 & 2 & 3 & 4 & 5 \\
\hline 1 & SDO & 2.72 & 1.16 & .93 & & & & & \\
\hline 2 & RWA & 3.18 & 1.07 & .82 & $.29 * *$ & & & & \\
\hline 3 & Status quo values & 4.27 & 1.14 & .94 & $.33^{* *}$ & $.43 * * *$ & & & \\
\hline 4 & Change values & 5.42 & 0.89 & .90 & $-.27 * *$ & -.16 & $-.38 * * *$ & & \\
\hline 5 & System Justification & 3.55 & 1.32 & .89 & $.25^{*}$ & $.29 * *$ & .14 & -.05 & \\
\hline 6 & Political conservatism & 3.47 & 1.54 & .73 & $.44 * * *$ & $.56^{* * *}$ & $.33 * *$ & -.10 & $.18^{\dagger}$ \\
\hline
\end{tabular}

Note. ${ }^{\dagger} p<.10 . * p<.05 . * * p<.01 . * * * p<.001$

a all values are Cronbach's Alpha, except Political Conservatism, which is $r$ due to a two-item measure. 


\section{Discussion}

Our aim for this study was to create reliable and valid measures for change values and status quo values. The results showed discriminant validity for change and status quo values, in that the values were statistically distinct from each other, as well as distinct from other political ideological orientations such as SDO and RWA. The factor structure revealed clear and distinct factors of change values and status quo values. Items that strongly loaded on these factors can be used to create reliable measures of each value. In addition, the finding that items assessing status quo and change values did not load onto a single factor supports our assertion that change and status quo do not fall on opposite ends of a single value dimension. The finding that these values are also empirically distinct from other personally-held ideological beliefs about the proper order of the world lends support to their potential unique role in predicting appraisals of conflict and subsequent collective action.

Despite the clear distinction revealed between values and the other constructs measured in Study 2, we observed that endorsement of each value was correlated with endorsement or rejection of different ideological orientations. Endorsing unequal (SDO) or aggressively authoritarian (RWA) social systems have been shown to predict social attitudes (e.g., prejudice, discrimination), and also shape collective appraisals of group conflict (e.g., identification, felt injustice; for a review see Sibley, Wilson, \& Duckitt, 2007). Recent work has also shown that endorsing these ideologies can shape appraisals of a group conflict context, and influence outsiders' willingness to take collective action on behalf of each group engaged in conflict (Saeri et al., 2015). Taken as a whole, the results of Study 2 suggest that the values of change and status quo are linked with, but are distinct from, ideological worldviews about social power, group inequality, and the proper order of societies. This, then, suggests that personal values can shape individuals' specific interpretations and appraisals of novel group conflict and inequality. We directly tested the predictive validity of change and status quo values in Study 3. 


\section{Study 3}

In Study 3, we sought to examine directly how endorsing change values and, separately, status quo values, might uniquely affect appraisals of a group conflict. Personal universal values are described as stable over time (Schwartz, 1992). But much of collective action research examines instantaneous appraisals of a group conflict situation. In that context, causal pathways between personal values and contextual appraisals are difficult to disentangle. We thus use a two-stage design for Study 3 to assist in the inference of causation. In the first stage (Time 1), we measured individuals' change and status quo values, and their political ideological orientations. At the second stage (Time 2), we measured contextual appraisals of a novel and fictional instance of group conflict and subsequent willingness to take collective action. We predicted that Time 1 change and status quo values would predict Time 2 appraisals, and that Time 2 appraisals would be associated with Time 2 willingness to take collective action. We measured context-specific appraisals of group identification, felt anger at the opposing group, and perceived group efficacy for each group engaged in a fictional conflict: a (high-status) government, and a (low-status) protestor group.

\section{Method}

Participants, Design, and Procedure. We initially recruited 221 US residents from Amazon Mechanical Turk to participate in a two-stage study. All participants who completed the Time 1 measures $(N=205)$ were invited to complete the Time 2 part of the study; the final sample thus included 159 participants who completed both questionnaires (Time 2 response rate $=78 \%$ ). All participants who completed both stages of the study, and who successfully answered comprehension checks at Time 2 were retained for analysis. Participants were paid USD $\$ 0.20$ to complete Time 1 , and USD $\$ 0.80$ to complete Time 2 . The final sample $(N=148)$ included participants aged between 18 and $71(\mathrm{M}=36.42, \mathrm{SD}=12.23)$ included $75(50.7 \%)$ women. The majority of participants $(n=120,81 \%)$ were White or European American. 13 participants were Asian American, five (3\%) were African American, eight (5\%) were Hispanic or Latino/a, one was Middle Eastern, and one reported that they were Native/African American. One participant had not 
completed high school; 44 had completed high school only, 30 had completed an associate's degree, 55 had completed a bachelor's degree, and 18 reported that they had completed a master's degree or higher. The data for this study were collected in 2014 .

\section{Materials and Measures.}

Time 1. Participants were recruited from Amazon Mechanical Turk to complete an online questionnaire measuring change values, status quo values, Social Dominance Orientation (SDO), Right-Wing Authoritarianism (RWA), and political conservatism. RWA $(\alpha=.90)$ and political conservatism $(r=.69, p<.001)$ were measured identically to Study 2 . We also used a shorter version of the SDO with 4 items scored from 1, extremely oppose, to 10 , extremely favor $(\alpha=84$; Pratto et al., 2013).

To create measures of change and the status quo, we retained the Study 2 items that loaded strongly and uniquely on to the single relevant factor (see bolded items in Table 1). In total, we retained six items that measured endorsement of change as a value, and nine items that measured endorsement of the status quo as a value. For each construct, the items were averaged to create reliable measures of change values $(\alpha=.89)$ and status quo values $(\alpha=.95)$, where higher scores indicated more endorsement of that personal value.

At the end of the questionnaire, participants were asked to create and record a unique code (which contained no personally identifying information) to allow us to match their responses on the Time 1 and Time 2 questionnaires.

Time 2. Two days after completing the Time 1 questionnaire, we invited participants to complete the second part of the study. If they agreed to complete this second questionnaire, participants read about a hypothetical intergroup conflict in the fictional country of Silaria. In this scenario, participants read that the Silarian citizens had brought the capital city to a halt with protests over unsafe working conditions. The scenario depicted the Silarian government as considering a law that would allow for detention of citizen protestors, and employing the military and police to arrest some protestors described by the government as "ringleaders". 
After reading about the conflict, participants were asked to describe key details of the scenario to check for comprehension. They then completed a series of measures assessing their responses to the conflict, with the explicit instruction to respond as though the scenario were real. The measures assessed levels of group identification, felt anger, perceived efficacy, and intentions to participate in collective action on behalf of each group in the conflict.

Identification with each group. We used three items to assess the strength of identification participants felt with members of each group in conflict. The items were adapted from Leach et al. (2008) and were averaged to form a reliable measure of identification with the citizens $(\alpha=.89)$ and government $(\alpha=.91)$. An example item was "I feel a bond with the Silarian [citizens / government]".

Felt anger towards opposing group. We used three items to measure anger felt towards members of the "opposition" group in conflict. Felt anger is the affective component of perceived injustice, which is a well-established predictor of collective action (van Zomeren et al., 2008). In the current study, those people who support the citizens would feel anger towards the opposing group: government, and vice versa. The items were adapted from previous intergroup emotion work (Iyer, Schmader, \& Lickel, 2007) and were averaged to form a reliable measure of anger towards citizens $(\alpha=.87)$ and government $(\alpha=.87)$. An example item was "I feel outraged at the Silarian [citizens / government]".

Perceived efficacy of each group. We used three items to measure perceived efficacy of each group in the conflict, adapted from previous work (van Zomeren, Spears, Fischer, \& Leach, 2004). The items were averaged to form a reliable measure of the apparent efficacy of citizens ( $\alpha=$ .92) and government $(\alpha=.86)$. An example item was "If they work together, the Silarian [citizens / government] can achieve [their / its] goals."

Intentions to take collective action. We used three items to measure participants' willingness to take action on behalf of each group in the conflict. The items were averaged to form a reliable 
measure of intentions to act in support of citizens $(\alpha=.95)$ and government $(\alpha=.94)$. An example item was: "I am willing to take action on behalf of the Silarian [citizens / government]".

\section{Results and Discussion}

Analytic strategy. Descriptive statistics and bivariate correlations for the focal variables are presented in Table 3. We conducted a series of regressions to investigate the effect of personal values on context-specific appraisals of a group conflict —including group identification, felt anger, and perceived group efficacy — and the effect of these appraisals as proximal predictors of collective action intentions. In order to more fully understand the psychological processes that may lead to support for the government, compared to the processes that lead to support for citizen protestors, we conducted separate analyses to predict collective action intentions to support each target group. When predicting collective action to support the government, we examined how change and status quo values predicted identification with the government, anger felt towards the opposing protesters, and perceived efficacy of the government, and how these context-specific appraisals were each associated with willingness to take collective action in support of the government. When predicting collective action to support the citizen protestors, we examined how change and status quo values predicted identification with the citizen protestors, anger felt towards the government, and perceived efficacy of the protestors, and how these context specific appraisals were each associated with willingness to take action in support of the protestors.

We regressed each appraisal for each target group on the focal variables of status quo values and change values, and the covariates of SDO, RWA, and political conservatism. Results of analyses including the covariates are reported here for a conservative test of the unique effects of status quo and change values on appraisals of group conflict and collective action. The effects reported are robust to inclusion or exclusion of political conservatism, SDO and RWA in the analyses.

To summarise, six sets of regression were conducted: one for each context-specific appraisal (identification, anger, and efficacy) $\mathrm{x}$ one for each target group (government and protestors). In 
addition, we used bootstrapping with 5,000 resamples and 95\% confidence intervals to investigate the indirect effects of status quo and change values on intentions to take collective action in support of each group via context-specific appraisals.

Predicting action to support citizen protestors. The coefficients of each Time 1 variable's relationship with each Time 2 outcome variable are presented in Table 4. Overall, we found that Time 2 identification with the citizen protestors was significantly and positively predicted by Time 1 endorsement of change values, and significantly and negatively predicted by Time 1 Social Dominance Orientation and political conservatism. We observed the same pattern of results for Time 2 felt anger towards the government (i.e., the group opposing the citizens): Endorsing change was associated with more anger towards the government, while higher levels of SDO and increased political conservatism was associated with less anger. Endorsing change— but no other Time 1 variable - was associated with increased perceived group efficacy of the citizen protestors at Time 2. The more a participant endorsed change, the more efficacious they believed the citizens could be in achieving their goals. In contrast, status quo values did not significantly predict any of the appraisals sympathetic to the low-status citizen protestors.

We then tested a full model including all Time 1 variables and Time 2 appraisals as simultaneous predictors of Time 2 collective action intentions. Each Time 2 appraisal significantly and positively predicted intentions to take collective action on behalf of the citizen protestors: identification, $B=0.3516, S E=0.1267, p=.006,95 \%$ CI [0.1011, 0.6021]; felt anger, $B=0.3654$, $S E=0.0973, p<.001,[0.1730,0.5578]$; and perceived group efficacy, $B=0.2319, S E=0.0876, p$ $=.009,[0.0586,0.4051]$. Bootstrapping analyses revealed stable indirect effects of endorsing change on intentions to take collective action via each of the three appraisals: identification, $B=$ $0.1101, S E_{\mathrm{boot}}=0.0554,95 \% \mathrm{CI}_{\mathrm{boot}}[0.0299,0.2684]$, felt anger, $B=0.1109, S E_{\mathrm{boot}}=0.0579$, $[0.0258,0.2624]$, and perceived group efficacy, $B=0.0745, S E_{\mathrm{boot}}=0.0427,[0.0133,0.1930]$. There were no indirect effects of endorsing the status quo on collective action intentions. 
Predicting action to support the government. The coefficients for each relationship between the Time 1 variables and the Time 2 appraisals are detailed in Table 5. To summarize, a significant and negative association was found between endorsing change and identification with the government. The more strongly a participant endorsed change as a value in their lives, the weaker they identified with the government group. Endorsing change also negatively predicted felt anger towards the citizen protestors, while social dominance orientation significantly $(p=.047$, 95\% CI $[0.0009,0.1216])$ and positively predicted felt anger towards the citizen protestors. No Time 1 variables significantly predicted perceived efficacy of the government to achieve its goals.

Next, we tested a full model with all Time 1 variables and Time 2 appraisals as simultaneous predictors of Time 2 collective action intentions. In this model, identification with the government $(B=0.2126, S E=0.0586, p<.001,[0.0967,0.3285])$, anger towards the citizen protestors $(B=0.5320, S E=0.0908, p<.001,[0.3525,0.7116])$, and right-wing authoritarianism $(B$ $=0.1829, S E=0.0296, p<.001,[0.0929,0.2729])$ significantly and positively predicted intentions to take collective action in support of the government. In addition, bootstrap analyses revealed a stable indirect effect of endorsing change on intentions to take action via identification $(B=-$ $\left.0.0454, S E_{\mathrm{boot}}=0.0249,95 \% \mathrm{CI}_{\mathrm{boot}}[-0.1146,-0.0103]\right)$ and anger $\left(B=-0.1005, S E_{\mathrm{boot}}=0.0510,[-\right.$ $0.2319,-0.0243]$. No direct or indirect effects were found for endorsing the status quo. 
Table 3

Descriptive statistics and bivariate correlations for Study 3.

\begin{tabular}{|c|c|c|c|c|c|c|c|c|c|c|c|c|c|c|}
\hline & \multirow{2}{*}{ Variable } & \multirow{2}{*}{$M(S D)$} & \multicolumn{12}{|c|}{ Correlations } \\
\hline & & & 1 & 2 & 3 & 4 & 5 & 6 & 7 & 8 & 9 & 10 & 11 & 12 \\
\hline 1 & Change values & $5.59(0.91)$ & & & & & & & & & & & & \\
\hline 2 & Status Quo values & $4.02(1.28)$ & $-.44 * * *$ & & & & & & & & & & & \\
\hline 3 & SDO & $2.88(1.87)$ & $-.38 * * *$ & $.23^{* *}$ & & & & & & & & & & \\
\hline 4 & RWA & $2.93(1.28)$ & $-.30 * * *$ & $.37 * * *$ & $.30^{* * *}$ & & & & & & & & & \\
\hline 5 & Political conservatism & $3.38(1.56)$ & $-.36 * * *$ & $.29 * * *$ & $.43^{* * * *}$ & $.51 * * *$ & & & & & & & & \\
\hline & Government & & & & & & & & & & & & & \\
\hline 6 & $\begin{array}{l}\text { Identification with } \\
\text { government }\end{array}$ & $1.67(0.96)$ & $-.25 * *$ & .09 & $.20^{*}$ & $.19^{*}$ & $.18^{*}$ & & & & & & & \\
\hline 7 & Anger at citizens & $1.31(0.64)$ & $-.34 * * *$ & $.14^{\dagger}$ & $.29 * * *$ & $.21^{*}$ & $.18^{*}$ & $.53^{* * *}$ & & & & & & \\
\hline 8 & Efficacy of government & $4.17(1.43)$ & -.09 & .13 & .01 & -.07 & -.05 & .01 & .06 & & & & & \\
\hline 9 & $\begin{array}{l}\text { Intentions to act in } \\
\text { support of government }\end{array}$ & $1.37(0.81)$ & $-.28 * *$ & .10 & $.33^{* * * *}$ & $.37 * * *$ & $.19 *$ & $.53 * * *$ & $.63^{* * *}$ & .09 & & & & \\
\hline & Citizens & & & & & & & & & & & & & \\
\hline 10 & $\begin{array}{l}\text { Identification with } \\
\text { citizens }\end{array}$ & $5.64(1.03)$ & $.36^{* * * *}$ & $-.14^{\dagger}$ & $-.41 * * *$ & $-.27 * *$ & $-.39 * * *$ & $-.34 * * *$ & $-.27 * *$ & -.07 & $-.31 * * *$ & & & \\
\hline 11 & Anger at government & $4.58(1.25)$ & $.32 * * *$ & -.13 & $-.37 * * *$ & $-.18^{*}$ & $-.28 * *$ & $-.33^{* * *}$ & -.13 & -.04 & $-.22 * *$ & $.55^{* * *}$ & & \\
\hline 12 & Efficacy of citizens & $4.98(1.22)$ & $.27 * *$ & -.09 & $-.16^{\dagger}$ & -.04 & -.02 & -.09 & $-.24 * *$ & $-.38 * * *$ & -.13 & $.28^{* *}$ & .13 & \\
\hline 13 & $\begin{array}{l}\text { Intentions to act in } \\
\text { support of citizens }\end{array}$ & $4.79(1.55)$ & $.36^{* * * *}$ & -.13 & $-.32 * * *$ & -.04 & $-.29 * * *$ & $-.16^{*}$ & $-.23^{* *}$ & -.05 & -.05 & $.51 * * *$ & $.51 * * *$ & $.32 * * *$ \\
\hline
\end{tabular}

Note. All variables measured on a 1-7 scale, except Anger, which was measured on a 1-6 scale. ${ }^{\dagger} p<.10 . * p<.05 . * * p<.01 . * * * p<.001$. 
Table 4

Regression coefficients for Time 2 predictors supporting the low-status citizen protestors on each Time 1 predictor in Study 3.

Time 2 predictors in support of the protestors

\begin{tabular}{|c|c|c|c|c|c|c|c|c|c|c|c|c|c|c|c|}
\hline \multirow{2}{*}{ Time 1 predictors } & \multicolumn{5}{|c|}{ Identification with protestors } & \multicolumn{5}{|c|}{ Anger at government } & \multicolumn{5}{|c|}{ Perceived efficacy of protestors } \\
\hline & $B$ & $S E$ & $p$ & $95 \% \mathrm{CI}$ & $s r^{2}$ & $B$ & $S E$ & $p$ & $95 \% \mathrm{CI}$ & $s r^{2}$ & $B$ & $S E$ & $p$ & $95 \% \mathrm{CI}$ & $s r^{2}$ \\
\hline Change values & 0.25 & 0.10 & .013 & {$[0.05,0.44]$} & .03 & 0.28 & 0.13 & .026 & {$[0.03,0.53]$} & .03 & 0.38 & 0.13 & .003 & {$[0.13,0.64]$} & .06 \\
\hline Status quo values & 0.08 & 0.07 & .260 & {$[-0.06,0.21]$} & .01 & 0.05 & 0.09 & .534 & {$[-0.12,0.22]$} & .00 & 0.02 & 0.09 & .809 & {$[-0.15,0.20]$} & .00 \\
\hline SDO & -0.13 & 0.05 & .004 & {$[-0.22,-0.04]$} & .04 & -0.17 & 0.06 & .004 & {$[-0.28,-0.05]$} & .05 & -0.07 & 0.06 & .238 & {$[-0.19,0.05]$} & .01 \\
\hline RWA & -0.05 & 0.07 & .443 & {$[-0.19,0.09]$} & .00 & -0.01 & 0.09 & .957 & {$[-0.18,0.17]$} & .00 & 0.01 & 0.09 & .944 & {$[-0.18,0.19]$} & .00 \\
\hline $\begin{array}{l}\text { Political } \\
\text { conservatism }\end{array}$ & -0.13 & 0.06 & .030 & {$[-0.25,-0.01]$} & .03 & -0.09 & 0.08 & .230 & {$[-0.24,0.06]$} & .01 & 0.10 & 0.08 & .224 & {$[-0.06,0.25]$} & .01 \\
\hline
\end{tabular}


Table 5

Regression coefficients for Time 2 predictors supporting the high-status government on each Time 1 predictor in Study 3.

Time 2 predictors in support of the government

\begin{tabular}{|c|c|c|c|c|c|c|c|c|c|c|c|c|c|c|c|}
\hline \multirow{2}{*}{ Time 1 predictors } & \multicolumn{5}{|c|}{ Identification with government } & \multicolumn{5}{|c|}{ Anger at protestors } & \multicolumn{5}{|c|}{ Perceived efficacy of government } \\
\hline & $B$ & $S E$ & $p$ & $95 \% \mathrm{CI}$ & $s r^{2}$ & $B$ & $S E$ & $p$ & $95 \% \mathrm{CI}$ & $s r^{2}$ & $B$ & $S E$ & $p$ & $95 \% \mathrm{CI}$ & $s r^{2}$ \\
\hline Change values & -0.21 & 0.10 & .036 & {$[-0.41,-0.01]$} & .03 & -0.19 & 0.07 & .004 & {$[-0.32,-0.06]$} & .05 & -0.13 & 0.15 & .404 & {$[-0.43,0.18]$} & .00 \\
\hline Status quo values & -0.06 & 0.07 & .431 & {$[-0.19,0.08]$} & .00 & -0.02 & 0.05 & .625 & {$[-0.11,0.07]$} & .00 & 0.18 & 0.11 & .103 & {$[-0.04,0.39]$} & .02 \\
\hline SDO & 0.05 & 0.05 & .286 & {$[-0.04,0.14]$} & .01 & 0.06 & 0.03 & .047 & {$[0.00,0.12]^{\mathrm{a}}$} & .02 & 0.01 & 0.07 & .941 & {$[-0.14,0.15]$} & .00 \\
\hline RWA & 0.09 & 0.07 & .244 & {$[-0.06,0.23]$} & .01 & 0.05 & 0.05 & .278 & {$[-0.04,0.14]$} & .01 & -0.14 & 0.11 & .203 & {$[-0.36,0.08]$} & .01 \\
\hline $\begin{array}{l}\text { Political } \\
\text { conservatism }\end{array}$ & 0.02 & 0.06 & .797 & {$[-0.11,0.14]$} & .00 & -0.01 & 0.04 & .786 & {$[-0.09,0.07]$} & .00 & -0.06 & 0.09 & .560 & {$[-0.24,0.13]$} & .00 \\
\hline
\end{tabular}

a The lower confidence bound for this coefficient is 0.0009 . 


\section{General Discussion}

We began this paper with the central aim of discovering how values can shape appraisals of group conflict and subsequent collective action. In three studies, we defined and distinguished the content and structure of change and status quo values, and demonstrated that change values but not status quo values can affect outsiders' appraisals of group conflict and willingness to take collective action. In Study 1, we found that change as a value included themes of growth, novelty, avoidance of stagnation, and adapting to inevitability. Themes underlying participants' values of the status quo included security, predictability, and conformity. In addition, the values were mostly seen as exclusive: valuing the status quo was incompatible with valuing change. In terms of both value content and structure, our findings here broadly reflect Schwartz' (1992) work on universal values. In Study 2, we confirmed that endorsing change the status quo as values were statistically distinct from each other and from other personally-focused variables with the potential for conceptual overlap, including SDO, RWA, and political conservatism. SDO and RWA in particular have recently been found to shape appraisals of group conflict and subsequent collective action.

In Study 3, we extended the social identity model of collective action (van Zomeren et al., 2008) by examining how universal personal values might shape appraisals of a novel conflict context. These appraisals included group identification, felt anger at an opposition group, and perceived efficacy of a group. We found that endorsing change as a value not only influenced appraisals relevant to the low-status citizen group in the conflict, but also changed appraisals relevant to the high-status government group. The degree to which a person endorsed change as a value in their life led to more positive appraisals in support of the citizen group, and increased collective action intentions on behalf of the citizens. Conversely, endorsing change led to more negative appraisals of the government, and decreased collective actions on behalf of the government. Importantly, and in extension of Study 2, the 
relationship between endorsing change as a value and the appraisals of group identification, anger, and perceived group efficacy were maintained after statistically controlling for the political and ideological variables of Social Dominance Orientation, Right-Wing Authoritarianism, and political conservatism.

In contrast to the significant effects of change values on appraisals, status quo values did not predict either appraisals supporting a low-status citizen protestor group or appraisals supporting a high-status government group. But in Study 2, change and status quo were both associated with variables that have previously shown to predict collective action (Saeri et al., 2015). In Study 1, change and status quo values were both described as similarly rich in content, and were each endorsed as important in participants' lives. If endorsing change was shown to predict conflict appraisals, then so too should endorsing the status quo. So why then did endorsing status quo not lead to support for the group that sought to maintain the status quo (the government), or a rejection of support for the group that sought to destroy the status quo (the citizen protestors)?

Values are both personal goals that guide thought and action across situations, and a lens through which we see and act upon the world at large (Schwartz, 1994). A person who values the status quo seeks for the world as a whole to remain stable, routine, and secure, and also desires that same stability, routine, and security in their personal life. A conflict may arise, however, between these two domains of the personal and societal. If a threat to the status quo of the wider, societal domain arises, a person is motivated by their values to defend that status quo. But to act in this manner runs counter to their desire for maintaining the status quo in their personal domain. This cross-domain conflict in the expression of status quo values may lead to a lack of collective action. The extent to which the status quo threat is perceived as irrelevant to the self would potentially amplify this demobilizing effect of crossdomain conflict. 
In Study 3, participants read about a fictional conflict occurring in a society that was not their own. Although the conflict involved a threat to the stability, routine, and security of the foreign society, the apparent irrelevance of the conflict may have led participants to maintain the status quo in their personal domain (i.e., choose not to act, choose not to psychologically engage with the high-status government group). It is important to note that this cross-domain conflict may not be present for change values: acting to create change is consistent with both personal and societal desires for change. Thus, if a person values change, they will enact their value (change) in order to achieve the progress and novelty that they seek in the world even if that means intervening in a novel group conflict with an uncertain outcome.

This reasoning may explain why, in Study 3, we observed a significant effect of change values on context-specific appraisals of group conflict, but no significant effect of status quo values. It may be the case that outsiders to group conflict will always show weaker or null effects of status quo values on appraisals compared with change values. However, both change and status quo values may act to predict appraisals and collective action for people who are members of groups currently engaged in conflict: insiders. Future work that investigates how values shape collective action could also directly manipulate the selfrelevance of the group conflict to test this cross-domain conflict explanation.

An alternative explanation is that status quo values are associated with a passive (vs. active) motivational orientation (Deci \& Ryan, 2012) and prevention (vs. promotion) regulatory focus (Higgins, 2012). Previous work has shown that established antecedents such as anger and perceived efficacy are differentially powerful in mobilizing people to take collective action when the individual is under promotion focus compared to when the individual is under prevention focus (Zaal, Van Laar, Ståhl, Ellemers, \& Derks, 2012). If status quo values are indeed associated with more passive and prevention-focused 
behaviours, individuals may not appraise or take action in support of either a high-status government or low-status citizen protestors. Instead, they may choose strategic inaction to preserve the status quo. Future work could explore the potential association between status quo values, motivational orientation, and regulatory focus as a route to understanding the role of valuing the status quo in facilitating or hindering collective action among outsiders to conflict.

\section{Implications for theory}

In this paper we extend existing work on values and political action by showing that the personal values of change and status quo can predict established social psychological antecedents of collective action. In addition, we add to the growing body of work that has examined how stable, individually-focused beliefs can affect context-specific appraisals and collective action (Saeri et al., 2015; van Zomeren, 2013). Almost all work investigating how values can motivate political action (e.g., environmentalism) has occurred outside social psychology, and has not been updated or integrated with new insights from social identity and self-categorisation theories. We argue that personal values may provide a common ground on which to establish a shared identity. In Study 3, endorsing change values positively predicted identification with a low-status citizen protestor group and negatively predicted identification with a high-status government group. If shared values can form a basis for a shared identity, then values can not only mobilize collective action, but also provide a foundation for close, collective bonds and support across social categories and even geographic borders.

In this paper we also directly compared change and status quo values with established socio-political attitudes and ideologies, including Social Dominance Orientation (SDO; Pratto et al., 1994) and Right-Wing Authoritarianism (RWA; Altemeyer, 1996), in order to confirm the conceptual distinctiveness of personal values (Study 2) and discriminant predictive 
validity of personal values compared to these ideological variables (Study 3). We might have expected that these variables, especially RWA, to substantially overlap with endorsement of the status quo as a value. Key components of the RWA ideology include the desire for security and conformity, which are themes that were also identified by participants who said they valued the status quo. Despite this conceptual relationship, the small to moderate correlations between values and SDO, RWA, and political conservatism, as well as the unique effect of endorsing change values on context-specific appraisals of group conflict, suggest that personal values are distinct from these established constructs. One implication of this work is that social and political psychological work must not neglect the potential importance of personal values in shaping attitudes and behaviour in intergroup contexts.

The central finding of this paper - that personal values can shape collective action-is consistent with an emerging literature indicating that stable, individual-focused beliefs have implications for appraisals about collective constructs, such as group identification and perceived group efficacy (van Zomeren, 2013; Saeri et al., 2015). In addition, endorsement of change as a value explained unique variance in group conflict appraisals above and beyond existing work on political ideologies (Saeri et al., 2015). While earlier work has examined the role of individual beliefs in shaping appraisals of conflicts, the present work takes an important step back from the political ideologies studied by Saeri et al. (2015) and the 'moral convictions' of van Zomeren (2013). Valuing change versus the status quo is the highest order value identified by Schwartz (1992), and is a highly abstract, de-contextualised cognition. This body of work is especially important when seeking to understand how lessinvolved third parties or uninvolved outsiders might react to group conflicts. We argue here that abstract universal values, in addition to other variables such as SDO, RWA, and moral convictions (e.g., van Zomeren et al., 2011) shape outsiders' appraisals of which group in a conflict has suffered unjustly and deserves their support. Thus a richer understanding of these 
individual-focused variables is critical to explaining when — and for whom — third parties and outsiders may take collective action.

\section{Suggestions for future research}

In the present work, we simultaneously assessed SDO, RWA, political orientation, and the values of change and status quo. However, it is possible that values could act as antecedents of political attitudes and ideology, and we suggest that future work tease out these causal pathways. Duckitt and Sibley (2010a) have described SDO and RWA as components of political conservatism and underpinned by core beliefs about the world as a ruthless and competitive "jungle", and a dangerous and threatening place, respectively. Jost, Federico, and Napier (2009) describe the liberal-conservative political ideological continuum as shaped by openness vs. resistance to change, and acceptance vs. rejection of inequality.

Expanding on the question of causality, we conceptualised values in the present work as stable. But we do not argue that valuing change or valuing the status quo are somehow innate or immutable. We agree with Schwartz and colleagues (Schwartz, 1992; Schwartz et al., 2010) that the strength of endorsement of different values are a product of the social world and a past and present person's social identities, as well as antecedents of future social identification. Just as endorsing change may lead to increased identification with a group with the explicit goal of change (e.g., a group that wishes to change same-sex marriage from illegal to legal), belonging to and caring about one's membership of a group that endorses change as a part of its identity may well result in newly valuing change at a personal level. Future work may contribute to the literatures on both collective action and personal values by investigating how personal values may operate within a more dynamic model of collective action (e.g., the dynamic dual pathway model, van Zomeren, Leach, \& Spears, 2012).

In Study 3, we portrayed the low-status (disadvantaged) citizen group with the goal of social change, and the high-status (advantaged) government group with the goal of 
maintaining the status quo. This conflation was convenient to demonstrate that personal values can shape appraisals of group conflict and inequality. However, the conceptual overlap between values, political ideology, and goals of each group obscured how values may (or may not) motivate appraisals and mobilize action truly independently of political ideology and the social power position of each group in conflict. For example, change might be valued by groups that support progressive social reform, as well as groups that support corporate deregulation and free-market capitalism. Ideologically, one group may be labelled as progressive/left-wing and the other as conservative/right-wing (Feldman, 2013). Future work could thus investigate how values shape collective behaviour and action in explicitly political contexts. If a high-status group endorsed change values (e.g., pension reform) and a lowstatus group endorsed status quo values (e.g., rejecting reforms), which group would be supported by outsiders who valued change?

The conflation of values, ideology, and social power provided a more conservative test of the unique role of personal values in shaping conflict appraisals, but future work could disentangle these intricate relationships by modifying the details of the conflict context. Participants could encounter a group conflict in which both groups are of relatively equal social power, such as a lawsuit between a large multinational corporation and a government. In this case, the status quo might support equality, whereas change will result in a difference in resulting social power. In future research, the low-status group may be portrayed with the goal of maintaining the status quo and the high-status group portrayed with the goal of change, such as a conflict between citizens who wish to preserve a state pension, and a government that wishes to abolish it.

\section{Conclusion}

In this paper, we have sought to integrate the rich literatures of personal values and collective action in a desire to understand how outsiders may appraise and respond to group 
conflict when they encounter it for the first time. We found that valuing change, but not status quo, affected well-established psychological motivators for collective action. In addition, this relationship between endorsing change as a value and appraisals of a conflict context extended to both the high-status and low-status groups. This work thus adds to a growing body of literature that can illuminate how less-involved outsiders may come to support a particular group in an external conflict. 


\section{References}

Altemeyer, B. (1981). Right-wing authoritarianism. Winnipeg: University of Manitoba Press. Altemeyer, B. (1996). The authoritarian specter. Cambridge, MA, US: Harvard University Press.

Braithwaite, V. (1994). Beyond Rokeach's equality-freedom model: Two-dimensional values in a one-dimensional world. The Journal of Social Issues, 50(4), 67-94.

Braun, V., \& Clarke, V. (2006). Using thematic analysis in psychology. Qualitative Research in Psychology, 3(2), 77-101.

Duckitt, J., \& Sibley, C. G. (2010b). Right-wing authoritarianism and social dominance orientation differentially moderate intergroup effects on prejudice. European Journal of Personality, 24(7), 583-601. doi: 10.1002/per.772

Feldman, S. (2013). Political ideology. In L. Huddy, D. O. Sears, \& J. S. Levy (Eds.), The Oxford Handbook of Political Psychology (2nd ed., pp. 591-626). Oxford, UK: Oxford University Press. doi: 10.1093/oxfordhb/9780199760107.013.0019

Glasford, D. E., \& Caraballo, K. L. (2015). Collective action from a distance: Distance shapes how people view victims of injustice and decreases willingness to engage in collective action. Group Processes \& Intergroup Relations. doi: $10.1177 / 1368430215570505$

Ho, A. K., Sidanius, J., Pratto, F., Levin, S., Thomsen, L., Kteily, N., \& Sheehy-Skeffington, J. (2012). Social dominance orientation: Revisiting the structure and function of a variable predicting social and political attitudes. Personality and Social Psychology Bulletin, 38(5), 583-606. doi: 10.1177/0146167211432765

Iyer, A., Schmader, T., \& Lickel, B. (2007). Why individuals protest the perceived transgressions of their country: The role of anger, shame, and guilt. Personality and Social Psychology Bulletin, 33(4), 572-587. doi: 10.1177/0146167206297402

Jost, J. T., Federico, C. M., \& Napier, J. L. (2009). Political ideology: Its structure, functions, and elective affinities. Annual Review of Psychology, 60, 307-337. doi: 10.1146/annurev.psych.60.110707.163600

Kaiman, J. (2014, September 30). Hong Kong's umbrella revolution - the Guardian briefing. The Guardian. Retrieved from http://www.theguardian.com/world/2014/sep/30/-sphong-kong-umbrella-revolution-pro-democracy-protests

Kay, A. C., \& Jost, J. T. (2003). Complementary justice: effects of "poor but happy" and "poor but honest" stereotype exemplars on system justification and implicit activation 
of the justice motive. Journal of Personality and Social Psychology, 85(5), 823. doi: $10.1037 / 0022-3514.85 .5 .823$

Leach, C. W., van Zomeren, M., Zebel, S., Vliek, M. L. W., Pennekamp, S. F., Doosje, B., . . . Spears, R. (2008). Group-level self-definition and self-investment: A hierarchical (multicomponent) model of in-group identification. Journal of Personality and Social Psychology, 95(1), 144-165. doi: 10.1037/0022-3514.95.1.144

Saeri, A. K., Iyer, A., \& Louis, W. R. (2015). Right-Wing Authoritarianism and Social Dominance Orientation predict outsiders' responses to an external group conflict: Implications for identification, anger, and collective action. Analyses of Social Issues and Public Policy, 15(1), 303-332. doi:10.1111/asap.12081

Mavor, K. I., Louis, W. R., \& Sibley, C. G. (2010). A bias-corrected exploratory and confirmatory factor analysis of right-wing authoritarianism: Support for a three-factor structure. Personality and Individual Differences, 48(1), 28-33. doi: 10.1016/j.paid.2009.08.006

Pratto, F., Çidam, A., Stewart, A. L., Zeineddine, F. B., Aranda, M., Aiello, A., ... Henkel, K. E. (2013). Social dominance in context and in individuals: contextual moderation of robust effects of social dominance orientation in 15 languages and 20 countries. Social Psychological and Personality Science, 4(5), 587-599. doi: $10.1177 / 1948550612473663$

Pratto, F., Sidanius, J., Stallworth, L. M., \& Malle, B. F. (1994). Social dominance orientation: A personality variable predicting social and political attitudes. Journal of Personality and Social Psychology, 67(4), 741-763. doi: 10.1037/0022-3514.67.4.741

Schwartz, S. H. (1992). Universals in the content and structure of values: Theoretical advances and empirical tests in 20 countries. In M. P. Zanna (Ed.), Advances in experimental social psychology (pp. 1-65). Academic Press.

Schwartz, S. H. (1994). Are There Universal Aspects in the Structure and Contents of Human Values? The Journal of Social Issues, 50(4), 19-45.

Schwartz, S. H., \& Bilsky, W. (1987). Toward a universal psychological structure of human values. Journal of Personality and Social Psychology, 53(3), 550-562. doi:10.1037/0022-3514.53.3.550

Schwartz, S. H., \& Bilsky, W. (1990). Toward a theory of the universal content and structure of values: Extensions and cross-cultural replications. Journal of Personality and Social Psychology, 58(5), 878-891. doi: 10.1037/0022-3514.58.5.878 
Schwartz, S. H., Caprara, G. V., \& Vecchione, M. (2010). Basic personal values, core political values, and voting: A longitudinal analysis. Political Psychology, 31(3), 421452.

Schwartz, S. H., Melech, G., Lehmann, A., Burgess, S., Harris, M., \& Owens, V. (2001). Extending the cross-cultural validity of the theory of basic human values with a different method of measurement. Journal of Cross-Cultural Psychology, 32(5), 519542. doi: 10.1177/0022022101032005001

Sibley, C. G., Wilson, M. S., \& Duckitt, J. (2007). Antecedents of men's hostile and benevolent sexism: The dual roles of social dominance orientation and right-wing authoritarianism. Personality and Social Psychology Bulletin, 33(2), 160-172.

Simon, B., \& Klandermans, B. (2001). Politicized collective identity: A social psychological analysis. American Psychologist, 56(4), 319-331. doi: 10.1037/0003-066X.56.4.319

Stern, P. C., \& Dietz, T. (1994). The Value Basis of Environmental Concern. The Journal of Social Issues, 50(3), 65-84.

Stern, P. C., Dietz, T., \& Kalof, L. (1993). Value orientations, gender, and environmental concern. Environment and Behavior, 25(5), 322-348. doi: $10.1177 / 0013916593255002$

Stern, P. C., Dietz, T., Abel, T., Guagnano, G. A., \& Kalof, L. (1999). A value-belief-norm theory of support for social movements: The case of environmentalism. Human Ecology Review, 6(2), 81-98.

Subašić, E., Reynolds, K. J., \& Turner, J. C. (2008). The political solidarity model of social change: dynamics of self-categorization in intergroup power relations. Personality and Social Psychology Review, 12(4), 330-352. doi: 10.1177/1088868308323223

Subašić, E., Schmitt, M. T., \& Reynolds, K. J. (2011). Are we all in this together? Covictimization, inclusive social identity and collective action in solidarity with the disadvantaged. British Journal of Social Psychology, 50(4), 707-725. doi: 10.1111/j.2044-8309.2011.02073.x

The Canadian Press. (2014, April 20). Pro-marijuana protesters hit Parliament Hill. CBC News. Retrieved from http://www.cbc.ca/news/canada/pro-marijuana-protesters-hitparliament-hill-1.2616223

Thomas, E. F., McGarty, C., \& Mavor, K. I. (2009). Aligning identities, emotions, and beliefs to create commitment to sustainable social and political action. Personality and Social Psychology Review, 13(3), 194-218. doi: 10.1177/1088868309341563 
van Zomeren, M. (2013). Four core social-psychological motivations to undertake collective action. Social and Personality Psychology Compass, 7(6), 378-388. doi: $10.1111 / \mathrm{spc} 3.12031$

van Zomeren, M., Leach, C. W., \& Spears, R. (2012). Protesters as "Passionate Economists": A dynamic dual pathway model of approach coping with collective disadvantage. Personality and Social Psychology Review, 16(2), 180-199. doi: $10.1177 / 1088868311430835$

van Zomeren, M., Postmes, T., \& Spears, R. (2008). Toward an integrative social identity model of collective action: A quantitative research synthesis of three sociopsychological perspectives. Psychological Bulletin, 134(4), 504-535. doi: 10.1037/0033-2909.134.4.504

van Zomeren, M., Postmes, T., \& Spears, R. (2012). On conviction's collective consequences: integrating moral conviction with the social identity model of collective action. The British Journal of Social Psychology, 51(1), 52-71.

van Zomeren, M., Postmes, T., Spears, R., \& Bettache, K. (2011). Can moral convictions motivate the advantaged to challenge social inequality? Extending the social identity model of collective action. Group Processes \& Intergroup Relations, 14(5), 735-753. doi: $10.1177 / 1368430210395637$

van Zomeren, M., Spears, R., Fischer, A. H., \& Leach, C. W. (2004). Put your money where your mouth is! Explaining collective action tendencies through group-based anger and group efficacy. Journal of Personality and Social Psychology, 87(5), 649-664. doi: 10.1037/0022-3514.87.5.649

Wright, S. C. (2010). Collective action and social change. In J. Dovidio, M. Hewstone, P. Glick, \& V. Esses (Eds.), The SAGE handbook of prejudice, stereotyping and discrimination (pp. 577-597). London, UK: SAGE. doi: 10.4135/9781446200919.n35 